\title{
A METHOD FOR THE STANDARDIZATION OF PERMEAM- ETERS AT HIGH MAGNETIZING FORCES
}

\author{
By Raymond L. Sanford
}

ABSTRACT

A description of apparatus suitable for the testing of standard magnetic test bars to be used for the standardization of magnetic permeameters with high magnetizing forces. A criterion is given for determining when accurate values have been obtained. Attention is called to the necessity that the standards shall be magnetically uniform.

\section{CONTENTS}

I. Introduction

II. Choice of a method.

III. Description of apparatus.

IV. Observations and results

V. Magnetic standards

VI. Summary

\section{INTRODUCTION}

With the advent and increasing use of cobalt magnet steels which, on account of their low permeability, require the application of relatively intense fields for magnetization, the question of magnetic testing with high magnetizing forces has come to have considerable practical importance. As the permeameters in general use for commercial magnetic testing have an upper limit of about 300 gilberts per centimeter, it has become necessary to develop methods to apply up to 1,000 gilberts per centimeter or even higher. Several such methods have been devised and are in use in various commercial laboratories. Comparative tests carried out under the auspices of a committee of the American Society for Testing Materials have revealed the fact that the results of measurements on the same sample by different methods generally do not show satisfactory agreement. The data do not show consistent differences between the methods and give no indication of the accuracy attained by any one method. The discrepancies are particularly noticeable in the observed values of coercive force, differences as great as 25 per cent being not uncommon. In view of the fact that considerable quantities of material are purchased on the basis of specifications as to magnetic quality, it is important to know the accuracy of the various commercial testing methods.

In a previous paper, ${ }^{1}$ the requirements of bars to be used as magnetic standards for the testing of permeameters were outlined and the Burrows permeameter was recommended for the calibration of magnetic

1 Sanford, Standards for Testing Magnetic Permeameters, B. S. Jour. Research, 4 (R P140), p. $177 ; 1930$. 
standards. As the upper limit of magnetizing force with this apparatus is of the order of 300 gilberts per centimeter, however, it is necessary to adopt some other method for calibration at higher values. An investigation of possible methods of calibrating standard bars at magnetizing forces up to 1,000 gilberts per centimeter was, therefore, undertaken with the end in view of selecting a suitable method for checking the accuracy of commercial permeameters in this range.

\section{CHOICE OF A METHOD}

The primary consideration in the choice of a standardizing method is accuracy. Furthermore, it should be possible to determine the accuracy attained without reference to measurements by any other method. An additional consideration in the present case is that, in order to determine the effect of size of sample on the accuracy of a given method, it is desirable that the standardizing method should not be restricted to any particular size or shape of specimen.

In any magnetic testing method, the principal condition which must be fulfilled for accurate results is that there shall be no leakage from that part of the bar covered by the test coils. Leakage leads to a nonuniform longitudinal distribution of magnetizing force, and thus produces an error in the observed results. Leakage can be eliminated in the case of a uniform straight specimen by applying the magnetizing force directly to the specimen by means of a magnetizing coil surrounding it and compensating for the reluctance of joints and yokes by means of extra windings over suitable parts of the magnetic circuit.

For magnetizing forces of the order of 1,000 gilberts per centimeter, however, there is some objection to surrounding the specimen with the magnetizing coil on account of heating due to the magnetizing current. It is known ${ }^{2}$ that the change in permeability brought about by an increase in temperature of only a few degrees is too great to be neglected in measurements in which an accuracy of 1 per cent is required. Furthermore, in order that the magnetizing current need not be excessive, it is well to include only a comparatively short length of the specimen in the test.

For measurements with relatively intense fields, several methods based upon the well-known isthmus method of Ewing and Low ${ }^{3}$ have been devised. In its original form, the method is not suitable for the present purpose because it requires the preparation of samples of a specified size and shape and is not adapted to the determination of points on the hysteresis loop. The modification of this method by Cheney, ${ }^{4}$ which is employed at the National Bureau of Standards, is limited to the use of a cylindrical specimen $6 \mathrm{~mm}$. in diameter. The methods of Campbell and Dye ${ }^{5}$ and of Webb and Ford ${ }^{6}$ are either subject to limitation as to size of sample or apply the magnetizing force by means of a coil surrounding the specimen. It was

S Sanford, Temperature Coefficient of Magnetic Permeability Within the Working Range, B. S. Sei. Paper No. 245; 13ull. 13. S., 12, P. 1, 1915. Spooner, 'Temperature Coeficients of Magnetic Permeability of sheet Stecl, Phys. Kev.,27, D. 183; 1926.

8 Ewing and Low, Magnetization of Iron in Strong Fields, Proc. Roy. Soc., 42, p. 200; 1887.

1 Cheriey, Magnetic Testiag of Straight Rods in Intense Fields, 3 . S. Sci. Papers 15 (No. 361), p. 625; 1920

"Campbell and Dye, The Magnetic Testing of Bars of Straight or Curved Form, J. Inst. Elec. Eng.,

5.,, $35 ; 1915$. 35

Wig and Ford, Precision Permeability Measurements on Straight Bars and Strips in the Region of II igh Permeability, J. Inst. Elec. Eng., 67, p. 1302; 1929. 
B. S. Journal of Research, RP279

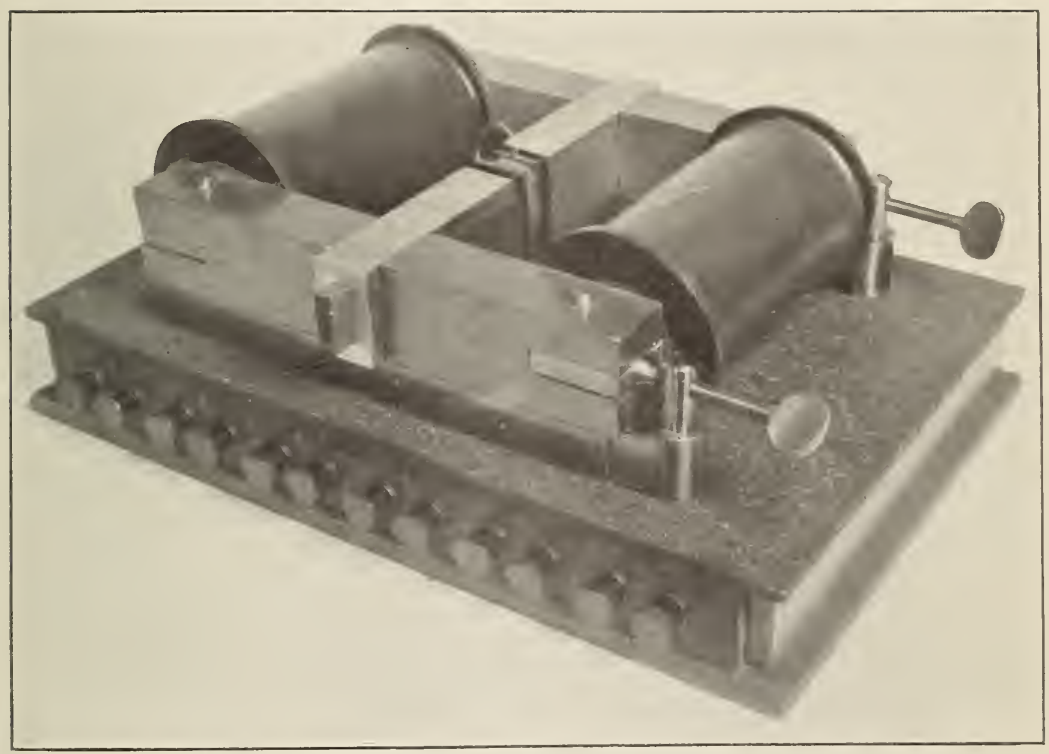

FIgURE 1.-Apparatus for magnetic measurements with high magnetizing forces 
decided, therefore, to investigate the possibilities of a slightly different arrangement in which the pole pieces are constructed so as to accommodate specimens of rectangular cross sections. A separate set of pole pieces and test coils is required for each size of specimen to be tested and the specimens must be accurately machined to size. Although this limitation would be serious from the standpoint of routine testing, it is relatively unimportant in standardization work where only a limited number of samples is required. With a method of this type, leakage from the specimen can not be eliminated, but, by proper proportioning of the parts of the magnetic circuit, the error due to leakage can be made negligible for magnetizing forces higher than about 50 gilberts per centimeter.

\section{DESCRIPTION OF APPARATUS}

Figure 1 shows the apparatus. The specimen is clamped in the symmetrical laminated yoke through pole pieces which serve to provide contact surfaces of large area and to shorten the length of the air gap in which the magnetizing field is measured. Special pole pieces and test coils are made to fit each specimen, which must be accurately ground to dimensions. The design of the pole pieces is indicated in the sketch of Figure 2. They consist of channel pieces of soft iron and filler strips

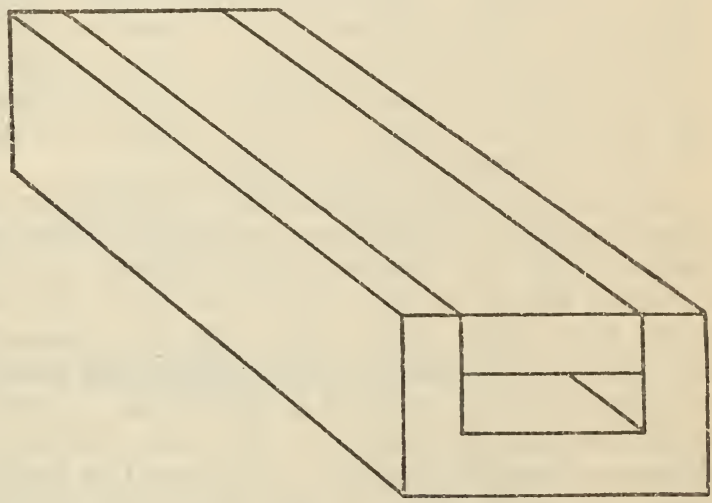

Figure 2.-Pole pieces of the same material, of such dimensions that when the specimen is inserted, there is a thickness of $1 \mathrm{~cm}$ at each side of the specimen. The filler strips are slightly over $1 \mathrm{~cm}$ thick so that they can be firmly clamped against the specimen when inserted in the yoke. Since the specimens are accurately ground to size, they are not strained by clamping, and this effect may be neglected. The separation between the poie pieces can be adjusted at will. The magnetomotive force is provided by means of magnetizing windings mounted on the yokes.

The test-coil system is wound on a split brass form having bakelite flanges. There are five test coils in all, $1 \mathrm{~cm}$ long and wound with 100 turns each. The first coil is wound directly on the form, insulated from the brass by a layer of thin paper. The second coil is separated from the first by a uniform layer of paper so that there is an annular space between them, and so on. With this arrangement, it is possible by connecting successive coils in series, opposing, to measure the field at four different distances from the specimen and thus by extrapolation to determine the field at the surface. This, according to theory, is equal to the magnetizing force acting on the specimen. 
For making the measurements, the usual battery, rheostats, reversing and selector switches, and resistance coils for sensitivity adjustment are used and need not be described in detail. The galvanometer is Leeds \& Northrup ballistic instrument having a free period of 24 seconds and an external resistance for critical damping of approximately 20,000 ohms. The instrument is of sufficiently high sensitivity so that it can be used with a parallel resistance as low as 200 ohms to give heavy overdamping, thus minimizing errors due to relatively slow flux change in the specimen. For calibration, a standard mutual inductance is used, the calibrating current being measured by a Brooks deflection potentiometer and standard shunts.

\section{OBSERVATIONS AND RESULTS}

As stated above, it is not possible to eliminate leakage from a specimen not surrounded by a magnetizing coil, but the effect can be minimized so as to be negligible in measurements with magnetizing forces exceeding about 50 gilberts per centimeter. It remains to determine what criterion can be used to determine that the proper conditions have been realized. The leakage conditions are affected by the relative areas of the pole face and specimen cross section and the distance by which the pole pieces are separated, which will be referred to simply as the gap.

Experiments were made with a specimen of hardened 36 per cent cobalt steel 1 by $3 \mathrm{~cm}$ in cross section. The test coils were so proportioned that, by using successive pairs, the field could be determined in zones whose aterage distances from the surface of the specimen were $1.35,3.30,5.35$, and $7.10 \mathrm{~mm}$, respectively. Typical results are given in Figure 3, which shows the distribution at three values of induction for gaps of 2 and $3 \mathrm{~cm}$. For the $3 \mathrm{~cm}$ gap the distribution is nearly uniform, the value falling off only slightly with the distance from the surface. At $2 \mathrm{~cm}$ the field increases with distance from the surface up to the $5.35 \mathrm{~mm}$ distance and then falls off. Extrapolation leads to the same value at the surface for either value of the gap. It is probable that, for a gap intermediate between the two, the radial distribution would be practically uniform as far as the test coils extend. The value of gap for uniform distribution will vary with the size of the specimen and the area of the pole pieces.

Although these results seemed to indicate that the correct value of magnetizing force had been obtained, there was some question whether there might not be a sharp drop in the field between the first zone and the surface due to the joint between the pole pieces and the specimen. In order to check this point, experiments were made with special cobalt-steel specimens prepared with great skill by the research department of the Westinghouse Electric \& Manufacturing Co. These specimens were $23 \mathrm{~cm}$ long with a section 2.50 by $1.85 \mathrm{~cm}$. $A$ hole approximately $9 \mathrm{~mm}$ in diameter was drilled longitudinally along the axis of each specimen. Even though they were drilled before the specimens were heat treated, the holes remained remarkably straight.

Pole pieces and test coils were made to fit the drilled specimens, and another test coil $1 \mathrm{~cm}$ long was wound on a cylindrioal form which would just fit in the hole. By means of this inner test coil the field within the specimen could be determined. Measurements were made with gaps of 3,4 , and $5 \mathrm{~cm}$. The values at 4 and $5 \mathrm{~cm}$ gave concordant 
results, and the extrapolated values agreed with those determined by means of the inner test coil as shown in Figure 4. For the $3 \mathrm{~cm}$ gap, however, the extrapolated values did not agree with those obtained with the inner coil. The extrapolated values were higher and the innercoil values were lower than for the longer gaps at the same induction. The reason for this is evident from the curves of Figure 5 which show the longitudinal distribution of $H$ within the specimen for the different values of gap. If the pole pieces are too near together, ieakage from the specimen to the pole-piece faces leads to a nonuniform longitudinal distribution of both $B$ and $H$ over the length of the specimen covered by the test coils.

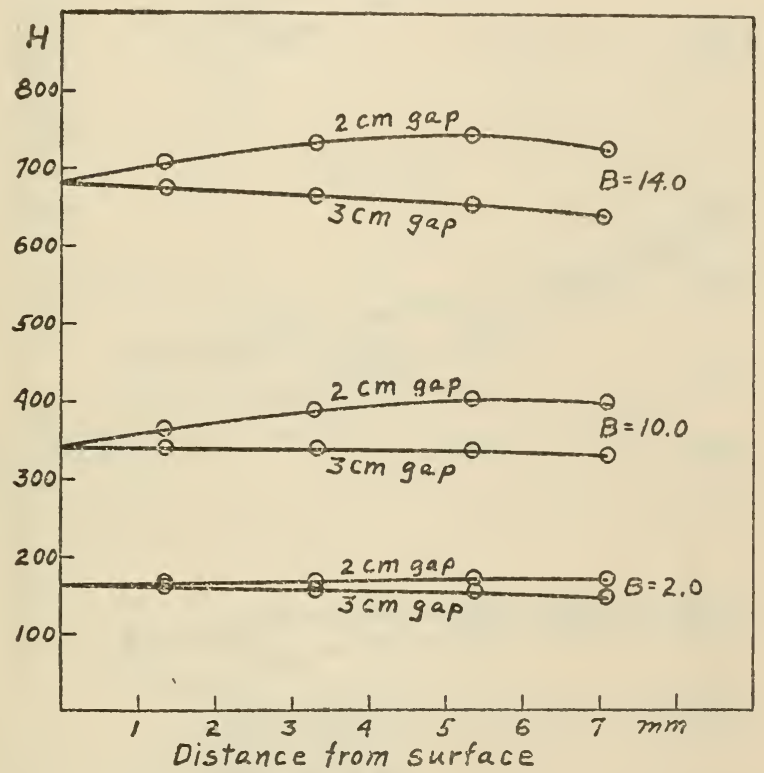

Figure 3.-Radial distribution of $H$ for 1 by $3 \mathrm{~cm}$ specimen

Magnetizing force, $\mathrm{H}$, in gilberts per centimeter. Induction, $\mathrm{B}$, in kilogausses

These results would seem to indicate that if the extrapolated ralues obtained with two or more gap distances are in agreement, this can be taken as a criterion that the leakage from the part of the specimen covered by the test coils is not excessive. The results thus obtained are estimated to be accurate within 1 per cent.

\section{MAGNETIĆ STANDARDS}

In an earlier paper, ${ }^{7}$ the writer has called attention to the importance of the degree of unifornity in bars which are to be used as magnetic standards. The effect of nonuniformity is most pronounced in the second stage of magnetization, where the slope of the normal induction curve is greatest, and is usually negligible in the third stage where the slope is smaller. At first thought, it might appear that this factor would be of even less importance where measurements are to be

7 Sanford, Standards for Testing Magnetic Permeameters, B, S, Jour. Research, 4 (RP110), p. 177 ; 1930. 
made with relatively intense magnetizing forces. As a matter of fact, the production of bars of cobalt magnet steel sufficiently uniform to be satisfactory for use as magnetic standards has proved to be the most difficult part of the problem. The curves shown in Figure 6 are

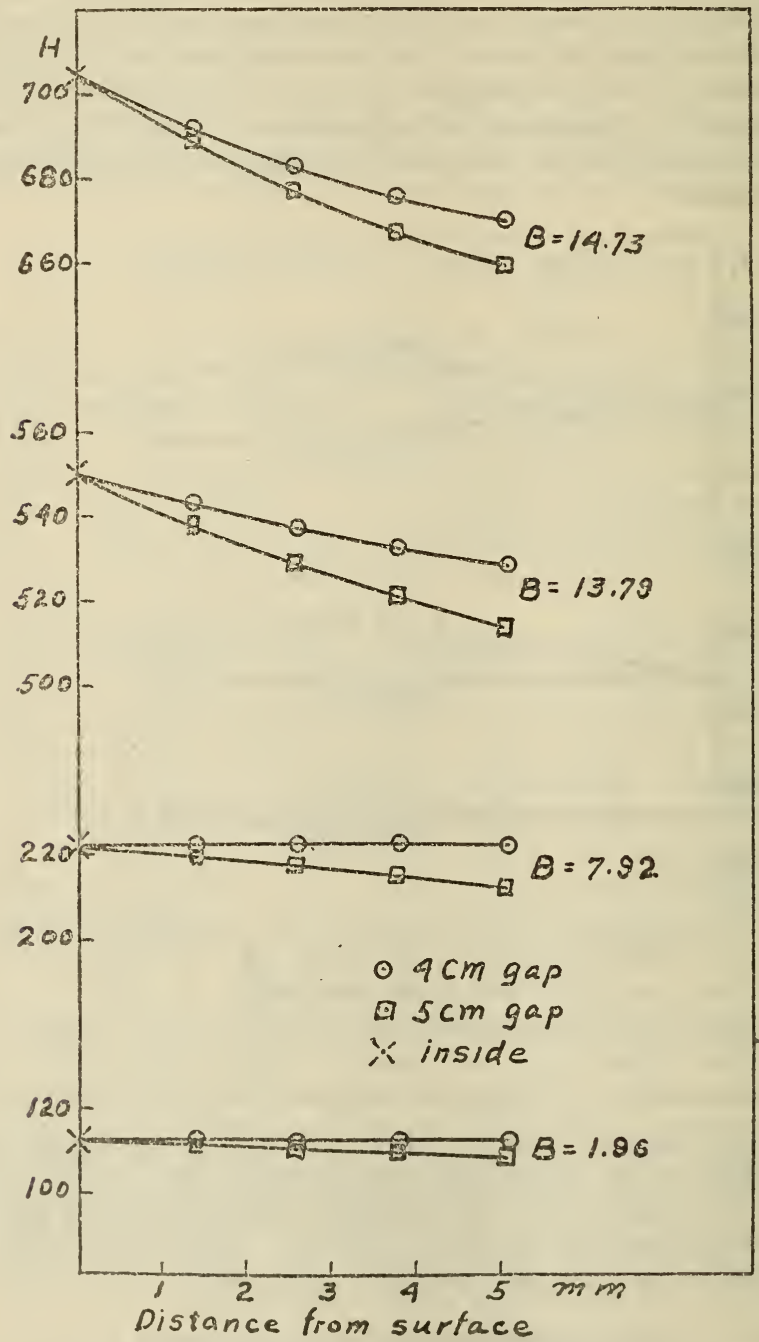

Figure 4.-Radial distribution of $H$ for drilled specimen

Magnotizing force, $\mathrm{H}$, in gilberts per centimeter. Induction, B, in kilogausses

typical of the conditions commonly found. The bar on which the observations were taken is magnetically soft at one end, the most conspicuous difference being observed in the coercive force, which varies in value from 60 to 160 gilberts per centimeter. It is obviously not fair to judge the accuracy of a method involving from 12 to 20 cm of the length of such a bar by the results obtained with another 
method inrolving only $1 \mathrm{~cm}$ of the bar, no matter how accurate the second method may be. It is probable that lack of uniformity is responsible in large part for the differences observed when identical

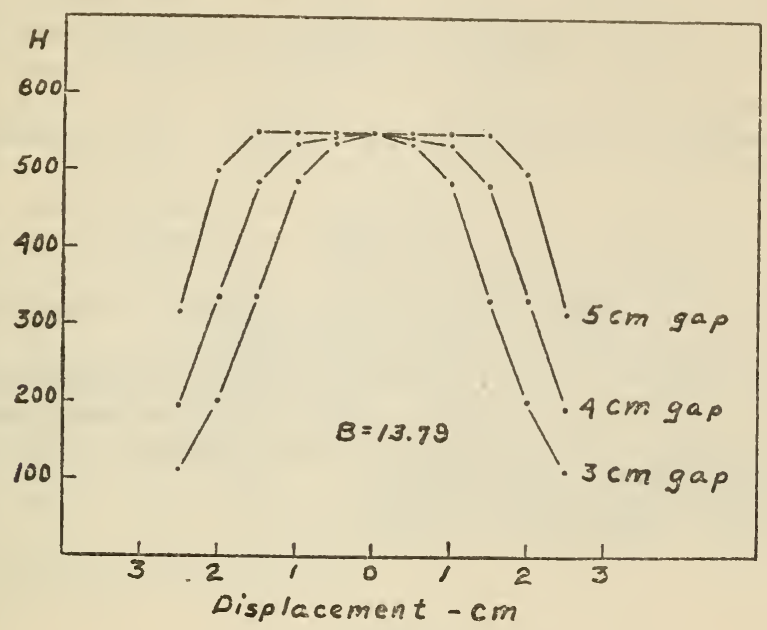

Figdre 5.-Longitudinal distribution of $I$

Magnetizing force, $\mathrm{H}$, in gilberts per centimeter. Induction, $\mathrm{B}$, in kilogausses

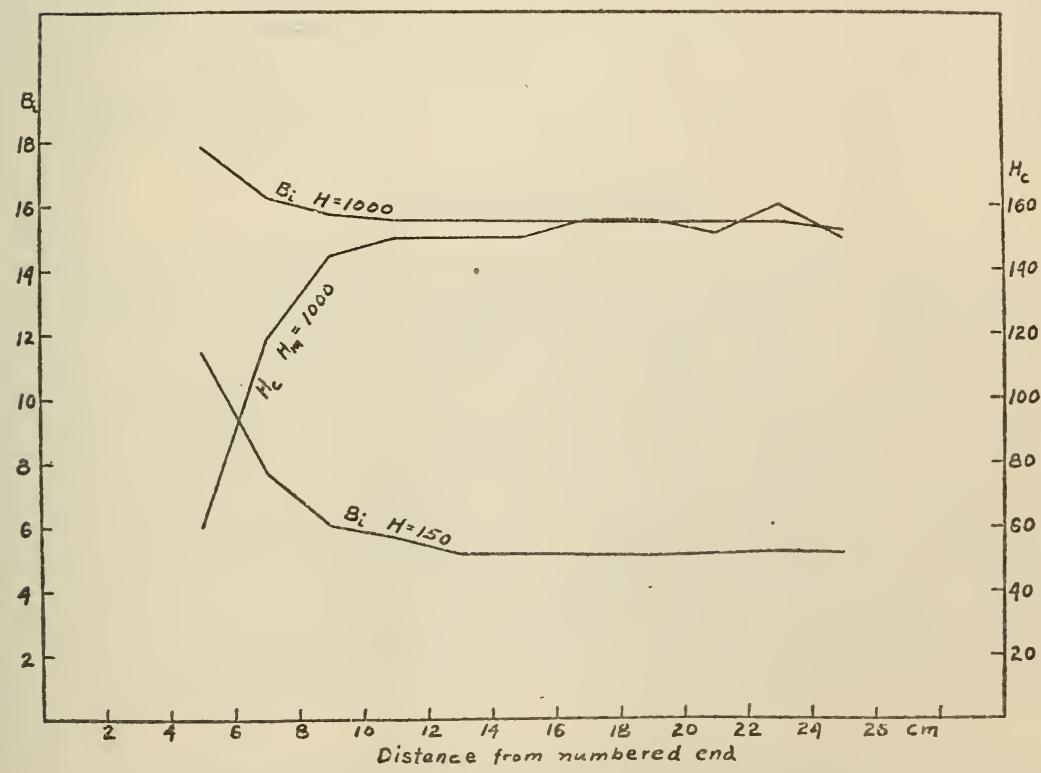

FIgURE 6.-Degree of uniformity of bar C-930

Intrinsic induction, $\mathrm{B}_{\mathrm{i}}$, in kilogausses. Coercive force, $\mathrm{H}_{\mathrm{c}}$, in gilberts per centimeter

bars are measured by different methods. It is still necessary, therefore, to take into account the uniformity of the bars to be used as magnetic standards even for measurements with high magnetizing forces. 


\section{SUMMARY}

The advent and increasing use of cobalt magnet steels requiring the application of relatively intense fields for magnetization has led to the development of a number of commercial permeameters for magnetic testing with high magnetizing forces. For the standardization of these instruments a method is required whose accuracy can be determined without reference to tests by any other method.

An adaptation of the well-known isthmus method is described, which, under proper conditions, gives an accuracy well within the allowable experimental error and which can be made to accommodate specimens of various shapes and sizes.

A criterion by which to determine whether or not the proper conditions for accuracy are obtained is given.

Attention is called to the importance of magnetic uniformity in bars to be used as magnetic standards, which must be taken into account in measurements with high magnetizing forces no less than in measurements in the lower ranges.

Washington, December 30, 1930. 